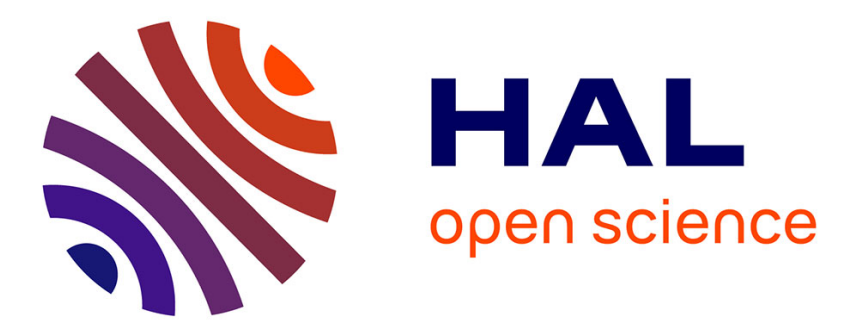

\title{
Fuzzy control of dissolved oxygen in a sequencing batch reactor pilot plant
}

Adama Traore, Stéphane Grieu, Sebastia Puig, Lluís Corominas, Frédérik Thiéry, Monique Polit, Jesus Colprim

\section{- To cite this version:}

Adama Traore, Stéphane Grieu, Sebastia Puig, Lluís Corominas, Frédérik Thiéry, et al.. Fuzzy control of dissolved oxygen in a sequencing batch reactor pilot plant. Chemical Engineering Journal, 2005, 111 (1), pp.13-19. 10.1016/j.cej.2005.05.004 . hal-01273091

\section{HAL Id: hal-01273091 \\ https://hal-univ-perp.archives-ouvertes.fr/hal-01273091}

Submitted on 11 Feb 2016

HAL is a multi-disciplinary open access archive for the deposit and dissemination of scientific research documents, whether they are published or not. The documents may come from teaching and research institutions in France or abroad, or from public or private research centers.
L'archive ouverte pluridisciplinaire HAL, est destinée au dépôt et à la diffusion de documents scientifiques de niveau recherche, publiés ou non, émanant des établissements d'enseignement et de recherche français ou étrangers, des laboratoires publics ou privés. 


\title{
FUZZY CONTROL OF DISSOLVED OXYGEN IN A SEQUENCING BATCH REACTOR PILOT PLANT
}

\author{
A. Traoré*, S. Grieu*, S. Puig**, L. Corominas **, F. Thiery*, M. Polit*, J. Colprim** \\ *Laboratoire de Physique Appliquée et d'Automatique, Université de Perpignan \\ 52 Avenue Paul Alduy, 66860 Perpignan, France \\ **Laboratori d'Enginyeria Quimica i Ambiental, Universitat de Girona \\ Campus de Montilivi, E-17071 Girona, Catalonia, Spain
}

\begin{abstract}
The present work is part of a global development of reliable real time control and supervision tools applied to wastewater pollution removal processes. In this processes, oxygen is a key substrate in animal cell metabolism and its consumption is thus a parameter of great interest for the monitoring. In this paper, are presented and discussed the results of the Dissolved Oxygen (DO) control in a SBR pilot plant based on a predefined 8 hours step-feed cycle. As first approach, the application of classical methods (on/off and PID) was considered. Due to the non linear character of the process, the PID parameter adjusting was very difficult and the obtained results showed a beating phenomenon around the setpoint. This phenomenon was more and less amplified according to the step of the cycle and the water pollution level. The second approach to achieve more stable DO control was based on a fuzzy logic strategy, taking into account the step and the difference between the measured DO and the setpoint. In this case, control action performances were highly improved. It's also shown that, using the fuzzy controller, the $\mathrm{pH}$ profile made it possible to clearly detect the ammonia valley during the aerobic phases. Thus, fuzzy logic proved to be a robust and effective DO control tool, easy to integrate in a global monitoring system for cost managing.
\end{abstract}

Keywords: SBR pilot plant, efficient and robust control, fuzzy logic, wastewater treatment plant, dissolved oxygen.

\section{Introduction}

One of the major evolutions in the conception field of automated systems concerns the taking into account, from the first phases, of their reliability. The reliability characterizes the system performances and returns the aptitude to correctly fulfil a fixed mission. It is related to the capability to resist to material, software or human failures, and to possible environmental aggressions. The reliability is partly obtained by design choices related to the system technological field : materials, dimensioning or manufacture [1]. Another part results of techniques concerned with information sciences and technologies : the reliability depends on an applicative architecture which, in addition of the system nominal functions, includes failures detection, localization and diagnosis functions. This architecture allows to detect operating mode changes, in particular related to environmental behaviour changes. It also rests on forecast functions, failures or aggressions accompaniment and command or objectives reconfiguration. All the above-mentioned functions ensure desired reactivity characteristics.

In the particular case of Sequencing Batch Reactors (SBR) technology, the instrumentation, the control and the automation are key factors when the process must be operated to achieve restricted discharge levels [2]. The dissolved oxygen (DO) is nowadays, one of the most important parameter to control because of its impact on the biological processes and the energy saving related to aeration [3].

Various works are dedicated to the DO control in bioprocesses $[4,5]$. The results obtained generally depend on the process complexity and also, on the control techniques used. The 
classical methods (on/off and PID) have largely been used but, due to the non-linear character of the bioprocesses and the lack of available models, the controllers were developed for specific operating and environmental conditions. Now, research interests are more and more directed towards using artificial intelligence techniques [6]. In this field, the control action offers the possibility of integrating expert knowledge and the technologic specificities of the process [7].

The work presented in this paper is part of a real-time control system study based on on-line calculated oxygen uptake rate (OUR), oxidation-reduction potential and $\mathrm{pH}$ profile to optimize the cycle length of the SBR for organic matter and ammonia removal $[3,8,9]$ in which the DO had a high influence. First of all, DO control was necessary in order to avoid final aerobic phases at high levels of DO. Due to the repeated anoxic-aerobic pairs, the beginning of anoxic phases at high DO levels concluded with time and carbon source reduction suitable for denitrification purposes[9]. For this reason, three kinds of DO control strategies were applied and compared: i) a simple ON/OFF control, ii) PID control and iii) a fuzzy logic based DO control.

The aim of this paper is to compare the obtained results using different types of DO control (on/off; PID and fuzzy logic control) in the SBR pilot plant installed in Celrà wastewater treatment plant (WWTP) treating urban wastewater.

\section{Materials and methods}

This section presents the SBR pilot plant installed in Celrà water treatment site and its biological specificities. The dissolved oxygen parameter is then described before the presentation of the different control strategies.

\subsection{The SBR pilot plant}

The SBR pilot plant set up in Celrà wastewater treatment plant treats about 700 litres of mixture of urban and industrial wastewater per day. The treatment is mainly based on organic matter and nitrogen removal. The SBR technology operates from a sequence of fill and draw cycles. These systems include a biological nutrient removal process. A fixed cycle of these characteristics, to achieve complete nitrification and denitrification (Fig. 1), was defined by previous lab-scale studies [10]. This 8 hours cycle, with 6 feeding steps and the alternation of aerobic and anoxic phases was also successfully applied in an other SBR pilot plant treating the Cassà wastewater.

A step-feed strategy for nitrogen removal means that the influent filling phases must be carried out under anoxic conditions in order to increase the denitrification efficiencies. It is important to take into account the alternation of aerobic and anoxic phases to permit a complete nitrogen removal. Fig. 2 shows the SBR pilot plant scheme. It is composed of a stainless-steel square reactor (1000 litres capacity) treating the influent wastewater. The monitoring and control system is based on probes from Endress-Hauser ${ }^{\mathbb{B}}$, cards and interfaces, developed over Labwindows ${ }^{\circledR}$, from National Instruments ${ }^{\circledR}$. The plant is equiped with DO-Temperature (OXIMAX-W COS 41), $\mathrm{pH}$ (CPF 81) and ORP (CPF 82) probes. The signals, filtered in a transmitter, are captured by a data acquisition card (PCI-6025E). The control is conducted using a power relay output board (SC-2062) which allowed an optimal equipment functioning. The software consisted of user-friendly interfaces and was able to repeat over time a previously defined operation cycle by controlling the switch on/off process 
of filling, purge, drawing of peristaltic pumps, mixing device and air supply. On-line mean values of $\mathrm{pH}$, ORP, DO and temperature were obtained every 5 seconds.
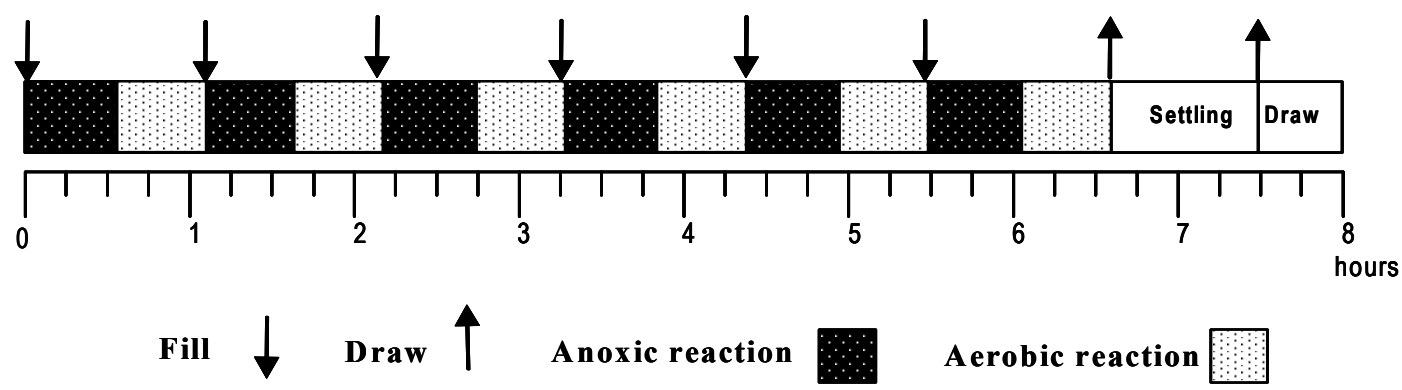

Fig. 1. Operational periods of the SBR pilot plant with filling strategy.

$8 \mathrm{H}$ cycle with 6 feeding steps and the alternation or aerobic and anoxic phases.

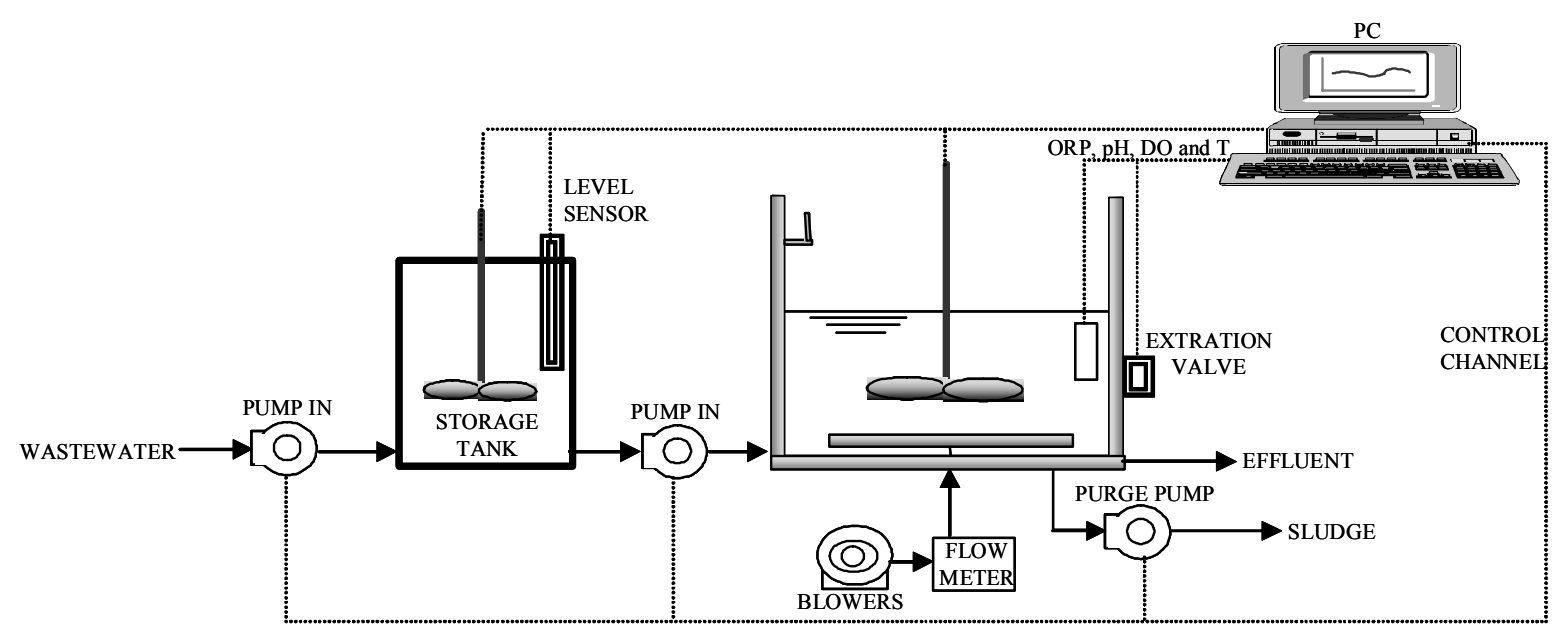

Fig. 2. Schematic overview of the SBR pilot plant installed in Celrà wastewater treatment site.

\subsection{The dissolved oxygen parameter}

The dissolved oxygen (DO) is an influential ecological parameter. DO is required for the respiration of aerobic microorganisms as well as all other aerobic life forms [11]. Its control is of extreme importance in the field of pollution removal biologic processes used by wastewater treatment plants. Its knowledge provides invaluable information related to the good behaviour of these processes $[9,12,13]$. The dissolved oxygen concentration strongly varies according to various system parameters like temperature, salinity or pressure.

\subsection{The control strategy}

The objective of the control in this work was to develop an on-line control action of the dissolved oxygen concentration, measured in a sequencing batch reactor. This concentration had to be stable and as near as possible to a setpoint, fixed from expert knowledge of the pollution present in the process considered.

The development of an efficient dissolved oxygen controller in Celrà-WWTP required to consider the following specificities:

- The dissolved oxygen probe provides measurements with a 30 seconds delay. This delay greatly affects the precision of real time control algorithms. 
- The six steps of the SBR pilot operation cycle are characterized by a progressive filling of the reactor. Thus, at each stage, a wastewater quantity to be treated is added. The air supply, which is carried out at the bottom of the reactor, requires applying a minimal voltage to the engine. This voltage (Table 1) depends on the water volume in the reactor and the pressure exerted by this volume or, simply, the step of the cycle.

- In the reactor, the dissolved oxygen evolution strongly depends on both water pollution level and micro-organisms behaviour.

Table 1

Minimal air supply voltage for each step

\begin{tabular}{ccc}
\hline Step of the cycle & Water volume & Minimal voltage \\
\hline 1 & 5171 & $0.5 \mathrm{~V}$ \\
2 & 5551 & $0.9 \mathrm{~V}$ \\
3 & 5921 & $1.3 \mathrm{~V}$ \\
4 & 6301 & $1.5 \mathrm{~V}$ \\
5 & 6671 & $2.3 \mathrm{~V}$ \\
6 & 6801 & $2.5 \mathrm{~V}$ \\
\hline
\end{tabular}

These specificities characterizing a strongly non-linear process, have been taken into account to develop 3 control strategies: on/off, PID and Fuzzy controllers. In case of an on/off regulation, the regulator instantaneously commands the system. As long as the regulated variable value is lower than the setpoint, the command variable is set to $100 \%$ (on). As soon as the values reach or exceed the setpoint, the command variable is set to $0 \%$ (off).

The Proportional-Integral-Derivative (PID) is the most common control methodology in process control. It is a continuous feedback loop that keeps the process flowing normally by taking corrective action whenever there is any deviation from the setpoint of a process variable. An error occurs when an operator manually changes the setpoint or when an event or a disturbance changes the load, thus causing a change in the process variable. The PID controller receives signals from sensors and computes corrective action to the actuators from a computation based on the error (proportional), the sum of all previous errors (integral) and the rate of change of the error (derivative). Detailed description on PID control strategy can be found in [14].

Fuzzy logic is the emulation of human reasoning on computers. Since it was introduced by Zadeh in 1965 [15], it has become popular in various applications, ranging from space shuttle control to industrial process control. The key concepts in fuzzy logic are the linguistic variable and membership function. A linguistic variable is a variable whose value is not a number but a word, described in terms of numerals by a membership function. This first step is called fuzzification. To perform fuzzy logic reasoning, a set of $I F-T H E N$ rules that emulate human reasoning needs to be specified. An IF-THEN rule is a simple statement that expresses cause and effect and offers a final decision. This operation is called inferences. At last this final output is turned into numerical value by deffuzification. Fuzzy inference systems have been proven to be powerful tools for solving complex problems. A detailed description of fuzzy logic applied to bioprocesses can be found in [16].

\section{Results and discussion}

In this section, the results with the different methods considered are presented. The first part is based on the comparison and the evaluation of the control action performances (DO stabilization around the setpoint). The on-line fuzzy controller structure, the rules bases and 
the fuzzy sets for each used variable are also presented and described in detail. the second part is devoted to the discussion of the impact of the control on the process monitoring with regard to cost managing possibilities.

Tests of dissolved oxygen control in Celrà-WWTP carried out using the simple on/off algorithm were based on the application of fixed voltages: $3.5 \mathrm{~V}$, when the DO concentration was lower than the setpoint $(2 \mathrm{mg} / \mathrm{l})$, and $0 \mathrm{~V}$, when it exceeded this setpoint. Let's note that the value of $3.5 \mathrm{~V}$ was empirically chosen to be appropriate (in term of compromise) for the six stages. As shown on figure 3, for a lower voltage, the DO tended to be lower than the setpoint for step 6. in addition, using the same kind of water, when this value $(3.5 \mathrm{~V})$ was increased, the DO kept beyond the setpoint for step 1. Concerning the on/off control quality with these values, the DO presented fluctuations and significant setpoint overtakings. Maintained oscillations (beating phenomenon near the setpoint) were due to the system inertia and the controller structure. This phenomenon were more or less amplified and the algorithm proved to be sensitive to the probe delay, the water pollution level, the bacteriological activity and the step of the cycle. The absence of intermediate states between (on) and (off) made the control action not very efficient, especially with small errors due to sensors.
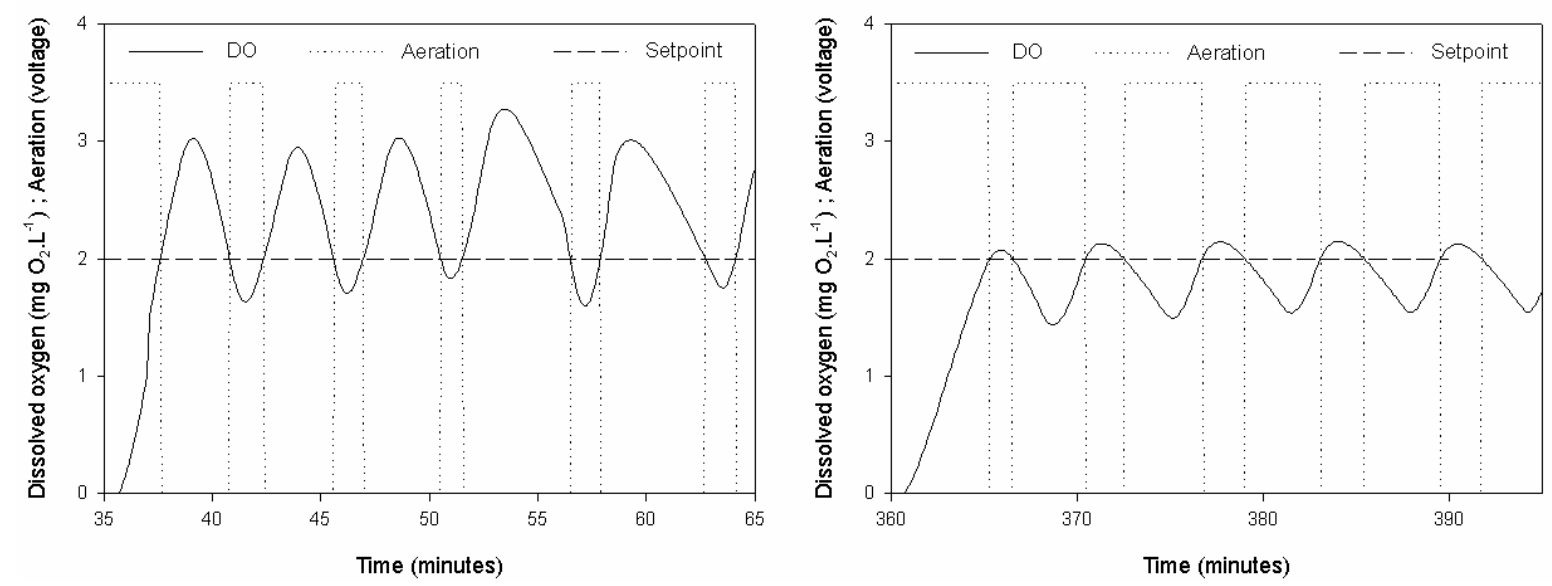

Fig. 3. Results of the on/off DO control. (left): on/off applied to step 1; (right): on/off applied to step 6.
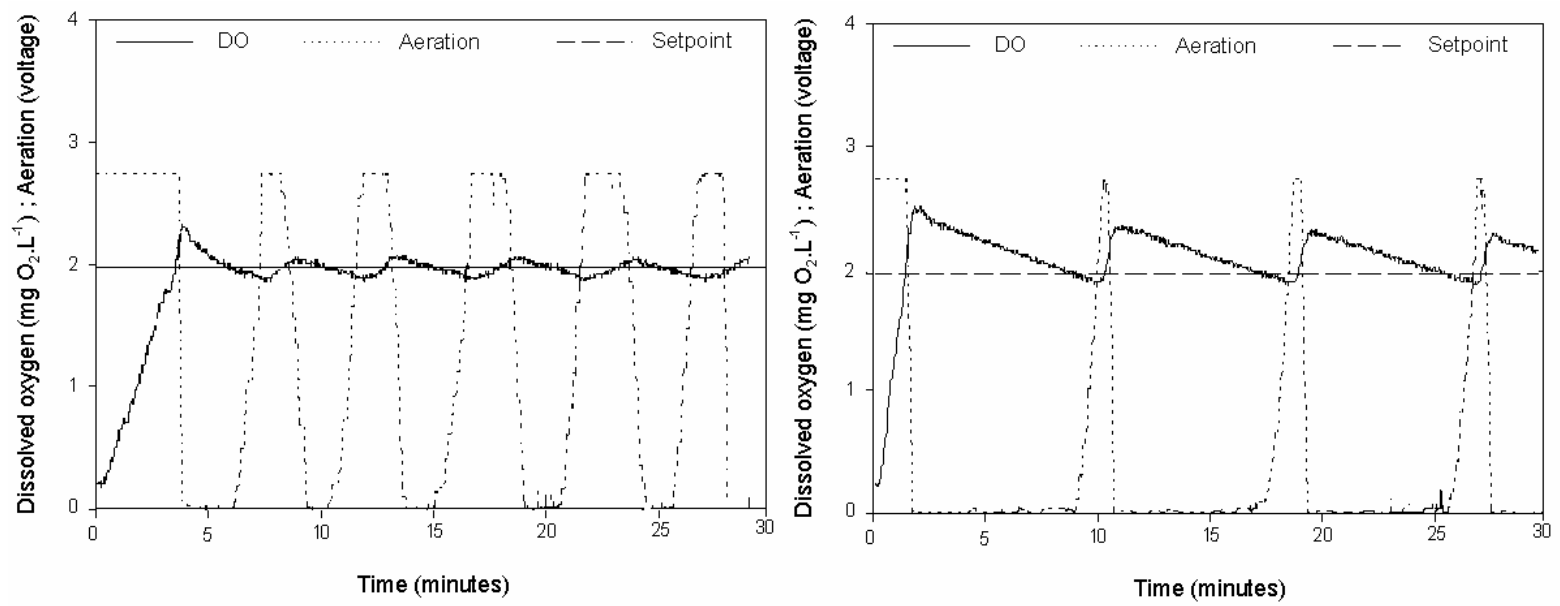

Fig. 4. Results of the PID DO control for step 1 and two different days.

The application of the PID control strategy was very hard since we did not have a model. Consequently, traditional techniques for parameter determination was delicate to realize. Fig. 
4 (left) shows the results obtained for step 1, with a well adjusted PID ( $\mathrm{Kc}=0.7, \mathrm{Ti}=0.02$, $\mathrm{Td}=300$ ). An important improvement can be noted about setpoint overtakings. However the application of the same PID to other stages did not guarantee any stability. To solve this problem, we considered the possibility to develop local controllers for each stage. But it was noticed that the same controller, applied to the same stage was strongly affected by daily changes in water pollution level (Fig. 4 (right)).

The conception of the fuzzy controller was based on an architecture of two inputs and one output. The first input is the difference between the setpoint and the measured dissolved oxygen $\left(\mathrm{DO}-\mathrm{DO} \mathrm{SP}_{\mathrm{SP}}\right.$. This difference is expressed by means of three fuzzy sets: negative (neg), zero (zero) and positive (pos) (Fig. 5.(up, left)). The second input is the step of the cycle (step), expressed by 6 fuzzy singleton sets (step 1 to step 6) in order to take into account the minimal voltage necessary to inject air in the reactor (Fig. 5.(up, right)). The output variable is the air injected into the reactor (Aeration), via the engine supply voltage. It is divided into 8 fuzzy sets as showed on Fig. 5 (down): small, ok 1 to ok 6, and big. Each of the 6 subsets "ok $\mathrm{i}^{\prime \prime}$ is centred on the voltage allowing to maintain the dissolved oxygen at the setpoint (DO $\mathrm{DO}_{\mathrm{SP}}$ is zero) for "step $\mathrm{i}$ ".

If ( $\mathrm{DO}-\mathrm{DO}_{\mathrm{SP}}$ is neg) the tension is increased while passing to the immediately higher subset. If (DO - $\mathrm{DO}_{\mathrm{SP}}$ is pos) the tension is decreased by applying the immediately lower subset. That justifies the two extreme subsets (small and big) corresponding, respectively, to a voltage reduction for step 1 and to a voltage increase for step 6 . This strategy is presented the rule base (Table 2).
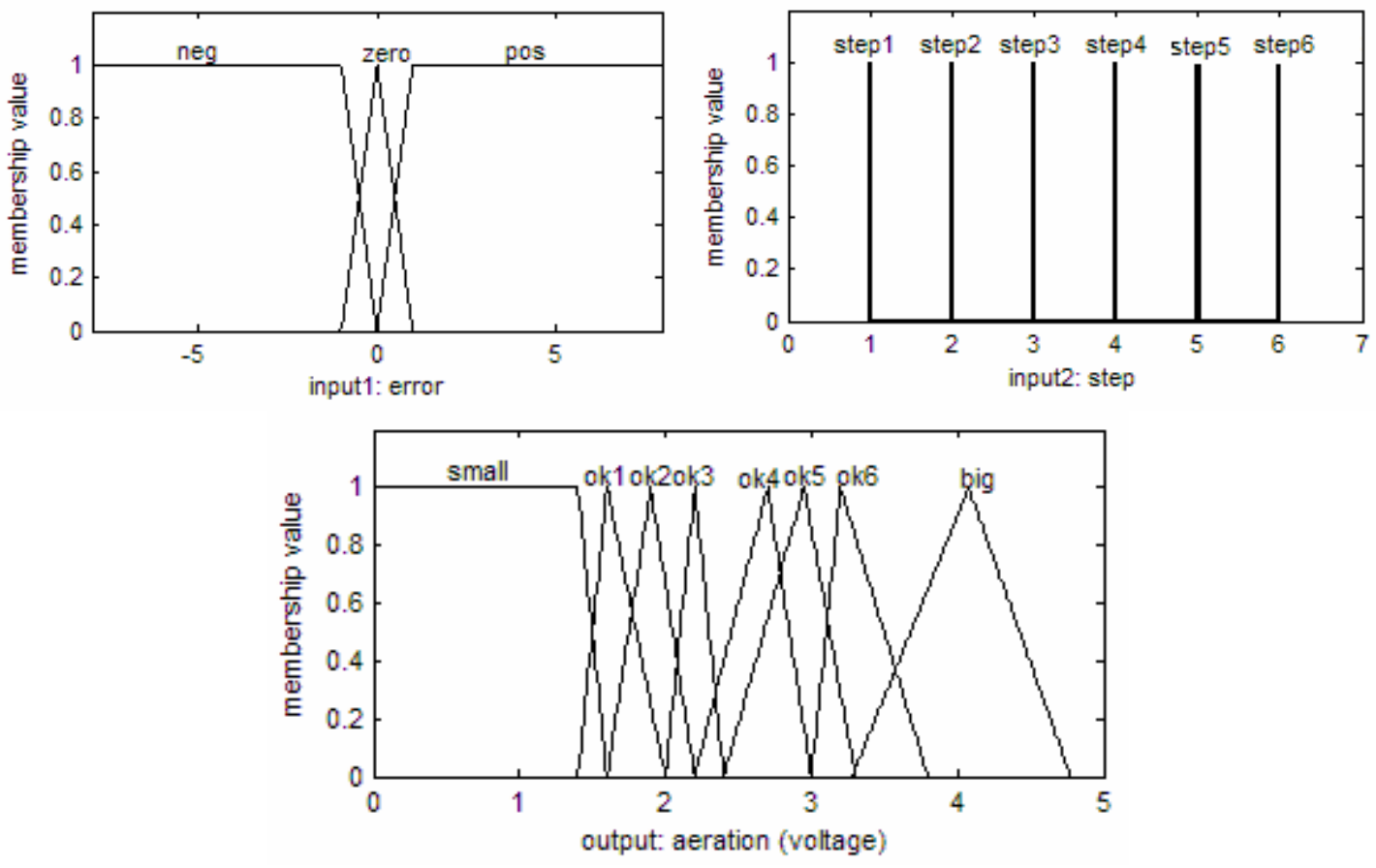

Fig. 5. Fuzzy sets of the on-line DO controller.

Table2

Rule base of the fuzzy on-line DO controller

\begin{tabular}{|c|c|c|c|c|c|c|c|}
\hline & & \multicolumn{6}{|c|}{ Step } \\
\hline & & 1 & 2 & 3 & 4 & 5 & 6 \\
\hline \multirow{3}{*}{$D O-D O_{S P}$} & neg & small & small & ok 1 & ok 2 & ok 3 & ok4 \\
\hline & zero & ok 1 & ok 2 & ok 3 & ok 4 & ok 5 & ok 6 \\
\hline & pos & ok 1 & ok 2 & ok 3 & ok 4 & big & big \\
\hline
\end{tabular}


Technically, a Mamdani fuzzy inference system is used. This kind of system allows a simplified representation and interpretation of the fuzzy rules. The integration of expert knowledge is thus easily realizable.
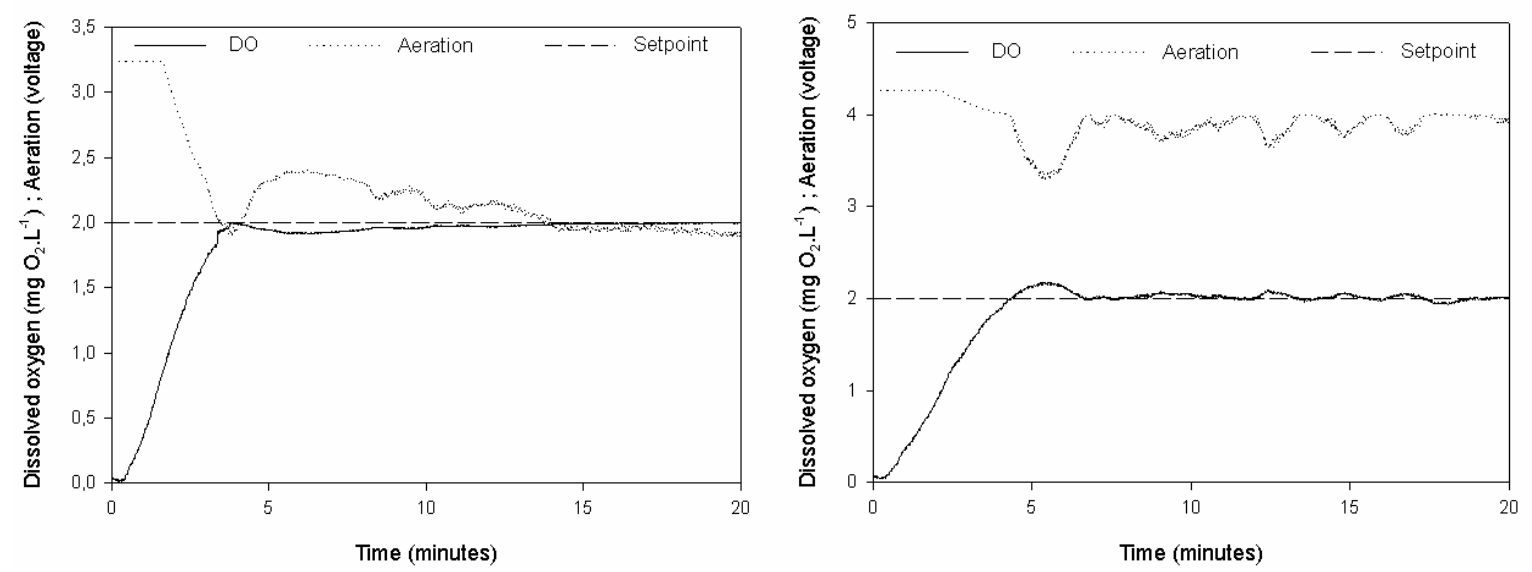

Fig. 6. Results of the fuzzy DO control. (left): fuzzy applied to step 1; (right): fuzzy applied to step 5.

Fig. 6 presents the results of the fuzzy DO control for steps 1 (left) and 5 (right). Contrary to the obtained results using on/off and PID methods, the results are very satisfactory. In fact, for each of the 6 steps, the control action made it possible to efficiently stabilize the dissolved oxygen concentration around the fixed setpoint $(2 \mathrm{mg} / \mathrm{l})$ and overtakings proved to be tiny.

Considering the previously evoked limitations about the PID parameter adjusting, the following discussions are restricted to the comparison of on/off and fuzzy controllers. The performance evaluation is focused on the possibility of clearly detecting the ammonia valley during the aerobic phases, using the $\mathrm{pH}$ profile.

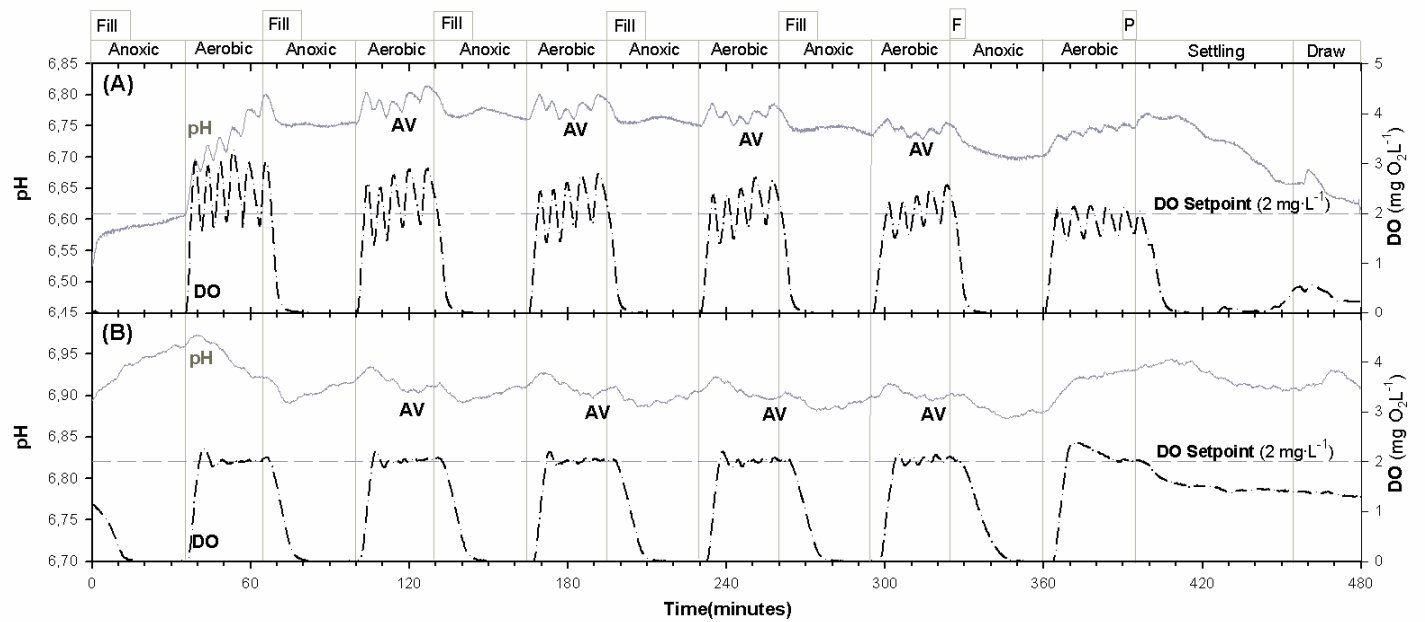

Fig. 7. $\mathrm{pH}$ and $\mathrm{DO}$ profiles during the 8 hours cycle length applied in the SBR pilot plant using on/off (A) and fuzzy (B) DO control.

Fig. 7 (A) shows a normal pattern for measured and calculated data results obtained when applying the on/off control strategy. Thus, because of the DO probe delay ( 30 seconds), significant setpoint overtakings had taken place. In Table 3, standard deviations are superior to 0.2 , when the DO measurements are ranging from 1.3 to $3.3 \mathrm{mgO}_{2} \cdot \mathrm{L}^{-1}$. The on/off aeration 
control was also responsible for an observed $\mathrm{pH}$ fluctuation. Even though, when ammonia depletion is achieved, a minimum appears in the $\mathrm{pH}$ profile, called Ammonia Valley (noted AV on Fig. 7), could be established from a full cycle profile during aerobic phases [9].

Table 3

Statistical results for DO control

\begin{tabular}{cccccccc} 
& & \multicolumn{6}{c}{ Step } \\
\cline { 3 - 8 } On/off & 1 & 2 & 3 & 4 & 5 & 6 \\
\hline \multirow{4}{*}{ Fuzzy } & Mean & 2.45 & 2.27 & 2.19 & 2.14 & 2.05 & 1.85 \\
& Min & 1.63 & 1.34 & 1.4 & 1.39 & 1.5 & 1.43 \\
& Max & 3.28 & 2.89 & 2.8 & 2.7 & 2.56 & 2.15 \\
& Std & 0.46 & 0.43 & 0.39 & 0.36 & 0.29 & 0.21 \\
\hline & Mean & 2.02 & 2.03 & 2.02 & 2.01 & 2.04 & 2.16 \\
& Min & 1.9 & 1.88 & 1.91 & 1.86 & 1.92 & 1.99 \\
& Max & 2.27 & 2.22 & 2.21 & 2.19 & 2.16 & 2.38 \\
& Std & 0.08 & 0.06 & 0.06 & 0.07 & 0.06 & 0.13 \\
\hline
\end{tabular}

An 8 hours cycle evolution of $\mathrm{pH}$ and DO after implementing fuzzy logic DO control is presented in Fig. 7 (B). One of the obtained advantages was the possibility of obtaining a continuous Oxygen Uptakes Rates measurement profile described in [3]. On the other hand, $\mathrm{pH}$ and DO fluctuations observed with the previous on/off control strategy were considerably reduced due to lower air flow injection variations. Measured DO values were always between 1.8 and $2.2 \mathrm{mgO}_{2} \cdot \mathrm{L}^{-1}$ and, the standard deviation, near 0.07 (apart from step 6). Compared to the on/off results, this represents a very strong overtakings reduction, with mean values closer to the setpoint. In spite of the displayed $\mathrm{pH}$ trend, the obtained data with coupled noise were enough to clearly detect the ammonia valley.

Various nitrification and denitrification cycles were carried out at the Celrà-WWTP in order to test both material (SBR pilot plant and sensors) and software (Labwindows ${ }^{\circledR}$ interface and fuzzy control) robustness. The system operation proved to be sure and effective, which indicates that choices, for both material and software, were judicious. Nitrification and denitrification cycles allowed, by means of a fuzzy on-line and effective control of the DO concentration, a satisfactory elimination of nitrogenous compounds (ammonia in the effluent close to zero) present in the wastewater treated by the SBR pilot plant. A more extended use of the fuzzy DO controller has been described in [9]. This control strategies have alos been applied to optimize the plant operation in terms of energy savings and effluent quality $[5,17]$.

\section{Conclusion}

This paper presented an effective and robust tool allowing on-line controlling the dissolved oxygen parameter during a nitrification and denitrification process. Thes process main objective is the elimination of nitrogenous compounds from a wastewater. The fuzzy logic based tool, developed under Labwindows ${ }^{\circledR}$, is of great interest for the SBR pilot plant (Sequencing Batch Reactor) installed at the Celrà-WWTP (Spain). It made it possible to carry out evaluations and effectiveness tests without disturbing the plant operation. Fuzzy algorithms proved, by their fault tolerance ability, to be robust and effective. They are very interesting tools in the field of control and supervision. The fuzzy controller offered the possibility to easily define a non-linear control law starting from vague system knowledge. Regulation tools like on/off and PID were also tested but had much more difficulty to carry out an effective control. Indeed, they could not prevent important setpoint overtakings, which had a negative impact on the effectiveness of the nitrification and denitrification process. 
The obtained results using a fuzzy controller showed the effectiveness of this tool and its superiority compared with traditional regulation techniques. The algorithm was not affected by the probe delay or the process strong non-linearity (biological state, water pollution level and system working variations). The fuzzy division of the used variables allowed a flexible information treatment and a gradual transition between the steps of the cycle. Due to its structure (subsets shape and rule base), the controller provided an excellent reaction capability.

Future prospects mainly concentrate on the integration of this on-line fuzzy controller into supervision and control tools already installed at the Celrà wastewater treatment plant. It can also be implemented on other plants according to a necessary adaptation of fuzzy sets and rule base in order to take into account the specificity of organic matter and nitrogen removal biologic processes.

\section{Acknowledgements}

The authors would like to thank CDTI-Spanish Government and INIMA Servicios del Medio Ambiente (Grupo OHL), Spanish Government (MCYT-DPI-2002-04579-C02), University of Girona (BR03/11), Catalan Government and the Languedoc Roussillon Region for their financial support in this study. In addition, the authors gratefully acknowledge Felip Arroyo, Montse Rubio and Maria Fabiana Teran for their valuable cooperation during the experimental study.

\section{References}

[1] D. L. Yu, T.K. Chang, D.W. Yu, Adaptive neural model-based fault tolerant control for multi-variable processes, Engineering Applications of Artificial Intelligence 18 (4) (2005) 393-411.

[2] G. Olsson, H. Aspegren, M. K. Nielsen, Operation and control of wastewater treatment - A scandinavian perspective over 20 years, Wat. Sci.Tech. 37 (12) (1998) 1-13.

[3] S. Puig, L. Corominas, A. Traore, J. Colomer, M. D. Balaguer, J. Colprim J., An on-line optimization of a SBR cycle for carbon and nitrogen removal based on on-line $\mathrm{pH}$ and OUR: the dissolved oxygen control role, 2nd IWA Conference on Instrumentation, Control and Automation for Water and Wastewater Treatment and Transport System, 2005.

[4] P. A. Vanrolleghem, Models in advanced wastewater treatment plant control, In: Proceedings Colloque Automatique et Agronomie, Montpellier, France, January 22-24 2003, pp. 26.

[5] A. Traore, L. Corominas, S. Puig S., S. Grieu, F. Thiery, M. Polit, J. Colprim, Dissolved oxygen control and phases duration optimization in a sequencing batch reactor pilot plant, 17th IMACS World Congress Scientific Computation, Applied Mathematics and Simulation, 2005.

[6] M. Galluzzo, R. Ducato, V. Bartolozzi, A. Picciotto, Expert control of DO in the aerobic reactor of an activated sludge Process, Computers and Chemical Engineering 25 (2001) 619-625.

[7] S. Grieu, A. Traoré, M. Polit, J. Colprim, Prediction of parameters characterizing the state of a pollution removal biologic process, Engineering Applications of Artificial Intelligence 18 (5) (2005) 559-573.

[8] L. Corominas, M. Rubio, S. Puig, M. T. Vives, J. Melendez, J. Colomer, M.D. Balaguer and J. Colprim, Online optimisation of step-feed operation in an urban wastewater nitrogen removal SBR by OUR determination and ORP analysis, 6th Specialist Conference on Small Water \& Wastewater Systems, 11-13 Febrer 2004 Fremantle WA, Australia, Org: IWA-AWA.

[9] S. Puig, L. Corominas, M. T. Vives, M. D. Balaguer, J. Colprim, J. Colomer, Development and implementation of a real-time control system for nitrogen removal using OUR and ORP as endpoints, Ind Eng Chem Res. 44 (2005) 3367-3373.

[10] M. T. Vives, M. D. Balaguer, R. García, J. Colprim, Study of the operational conditions for organic matter and nitrogen removal in a sequencing batch reactor, Scientia gerundensis 25 (2001), 103-114.

[11] Metcalf \& Eddy, Wastewater Engineering: Treatment and Reuse, Mc Graw Hill $4^{\text {th }}$ Edition, 2003. 
[12] G. Deronzier, S. Schetrite, Y. Racaulty, J. P. Canler, A. Lienard, Traitement de l'azote dans les stations d'épuration biologiques des petites collectivités, Collection Documentation technique, $n^{\circ} 25$, Cemagref-Editions, 2001.

[13] M. Mauret, F. Ferrand, V. Boisdon, M. Sperandio, E. Paul, Process using DO and ORP signals for biological nitrification and denitrification validation of a food-processing industry wastewater treatment plant on boosting with pure oxygen, Wat. Sci. \& Tech 44 (2-3) (2001) 163.

[14] W. L. Luyben, M. L. Luyben, Essentials of Process Control, McGraw-Hill Int. Editions, 1997.

[15] L. A. Zadeh, Fuzzy sets, Information and control (8) (1965) 338-353.

[16] D. E. Seborg, T. F. Edgar, D. A. Mellichamp, Process Dynamics and Control, 2nd Ed., John Wiley \& Sons, New York, 2004.

[17] L. Corominas, A. Traore, G. Sin, S. Puig, M. D. Balaguer, J. Colprim, P. A. Vanrolleghem, Model-based evaluation of an on-line control strategy for SBR's based on OUR and ORP measurements, 2nd IWA Conference on Instrumentation, Control and Automation for Water and Wastewater Treatment and Transport System ICA, 2005. 